\title{
DO QUE SE DIZ \\ AO QUE SE FAZ: \\ ANÁLISE DA \\ CONSTITUIÇÃO \\ DE UM LD \\ DE ITALIANO \\ PARA \\ ESTRANGEIROS
}

\section{DE LO QUE SE DICE A LO QUE SE HACE: ANÁLISIS DE LA CONSTITUCIÓN DE UN LD DE ITALIANO PARA EXTRANJEROS}

WHAT YOU SAY AND WHAT YOU DO: ANALYSIS OF THE CONSTITUTION OF AN LD OF

ITALIAN FOR FOREIGNERS

Jeferson Evaristo*

Universidade do Estado do Rio de Janeiro

RESUMO: Desde o surgimento da Abordagem Comunicativa (RICHARDS; RODGERS, 2003), a preocupação com o contexto de fala e de uso da língua passou a fazer parte da prática dos professores de Língua Estrangeira e, em certa medida, da sua formação. Mesmo com a perspectiva do ensino sendo orientada pela chamada teoria do "pós-método", contexto e uso situado da língua permanecem como fatores de atenção no ensino de LE (KUMARAVADIVELU, 2006). Apesar das diferentes formas de se conceber o ensino, o LD continua a ser prioritariamente o principal recurso pedagógico para o ensino-aprendizagem de línguas (VILAÇA, 2012; PAIVA, 2009), sendo frequentemente a única ferramenta disponível. Mas, não obstante a mudança de perspectivas, a existência de incoerências teórico-metodológicas se mantém, o que modifica/compromete o processo de aprendizado e significação dos alunos no idioma aprendido. Nesse contexto, nos propomos a analisar um livro didático de Italiano para estrangeiros - Chiaro!! A1 (Editora ALMA, 2010) - e observar/problematizar sua constituição, a partir da Linguística Aplicada (VILLAÇA, 2012; PAIVA, 2009; RICHARDS, 2006; TILIO, 2006; RICHARDS; RODGERS, 2003), investigando nas atividades de uma Unidade Didática (UD) em específico como se efetivam as indicações feitas pelo livro na sua autoapresentação e no índice da UD. Pretendemos com esta análise motivar uma maior discussão acerca da análise e crítica destes materiais, ampliando um debate necessário.

* Doutor em Língua Portuguesa pela UERJ (2020) e doutor em Letras Neolatinas (língua italiana) pela UFRJ (20l9). Atualmente é professor de Língua PortuguesanaUERJ. E-mail: jeff.evaristo2@gmail.com. 
PALAVRAS-CHAVE: Material didático. Língua estrangeira. Italiano.

RESUMEN: Desde la aparición del enfoque comunicativo (RICHARDS; RODGERS, 2003), la preocupación con el contexto de habla y de uso del lenguaje se ha convertido en parte de la práctica de los profesores de Lengua Extranjera y, en cierta medida, de su formación. Incluso con la perspectiva de la enseñanza guiada por la llamada teoría del "post-método", el contexto y el uso situado de la lengua permanecen como factores de atención en la enseñanza de LE (KUMARAVADIVELU, 2006). A pesar de las diferentes formas de concebir la enseñanza, el LD sigue siendo el principal recurso pedagógico para la enseñanza y el aprendizaje de lenguas (VILAÇA, 2012; PAIVA, 2009), siendo, frecuentemente, la única herramienta disponible. Pero, a pesar del cambio en las perspectivas, la existencia de inconsistencias teórico-metodológicas permanece, lo que modifica/compromete el proceso de aprendizaje y significación de los estudiantes en el idioma aprendido. En este contexto, proponemos analizar un libro didáctico de italiano para extranjeros: Chiaro! A1 (Editora ALMA, 2010) - y observar/problematizar su constitución, a partir de la Lingüística Aplicada (VILLAÇA, 2012; PAIVA, 2009; RICHARDS, 2006; TILIO, 2006; RICHARDS; RODGERS, 2003), investigando las actividades de una Unidad Didáctica (UD), particularmente, cómo se llevan a cabo las indicaciones hechas por el libro en su autopresentación y en el índice de la UD. Con este análisis pretendemos motivar una mayor discusión sobre el análisis y la crítica de estos materiales, ampliando un debate necesario.

PALABRAS CLAVE: Material didáctico. Lengua extranjera. Italiano.

ABSTRACT: Since the beginning of the Communicative Approach (RICHARDS; RODGERS, 2003), the concern with the context of speech and use of language has become part of the practice of foreign language teachers and, to a certain extent, their training. Even with the perspective of teaching being guided by the so-called "post-method" theory, context and localized use of language remain as attention factors in Foreign language teaching. (KUMARAVADIVELU, 2006). Despite the different ways of conceiving education, LD remains the main pedagogical resource for teaching and learning languages (VILAÇA, 2012; PAIVA, 2009), and is often the only tool available. But despite the change in perspectives, the existence of theoretical and methodological inconsistencies remains, which modifies / impairs the process of learning and meaning of the students in the language learned. In this context, we propose to analyze an Italian textbook for foreigners - Chiaro!! And to observe / problematize its constitution, from Applied Linguistics studies (VILLAÇA, 2012; PAIVA, 2009; RICHARDS, 2006; TILIO, 2006; RICHARDS; RODGERS, 2003), investigating in the activities of a Teaching Unit in specific how the indications made by the book in its self-presentation and in the teaching unit index are carried out. We intend with this analysis to motivate a greater discussion about the analysis and critique of these materials, expanding a necessary debate.

KEYWORDS: Coursebook. Foreign language. Italian Language.

\section{INTRODUÇÃO}

Uma das tarefas mais pertinentes ao ensino de línguas estrangeiras (LE) é a escolha dos materiais didáticos que serão utilizados. Naturalmente, essa escolha deve ser motivada por elementos anteriores - como a concepção de ensino-aprendizagem adotada, por exemplo - e seguir critérios objetivos e coerentes.

Cabe ao professor, então, decidir sobre quais materiais usar para a realização de um curso, tendo em vista que o livro didático (LD) é, ainda hoje, a base dos cursos de língua estrangeira (CRISTOVÃO; DIAS, 2009). Historicamente, ele tem um papel centralizador no ensino de LE, configurando-se como o principal recurso pedagógico para o ensino-aprendizagem de línguas (VILLAÇA, 2012; PAIVA, 2009; TILIO, 2006), e sendo "[...] muitas vezes o único material de acesso ao conhecimento tanto por parte de alunos quanto por parte de professores" (CRISTOVÃO; DIAS, 2009, p. 11). Como afirma Kumaravadivelu (2006, p. 84), o livro é muitas vezes confundido com o próprio método ${ }^{1}$.

\footnotetext{
${ }^{1}$ Segundo Richards e Rodgers (2003, p. 8), métodos seriam “[...] uma série de princípios essenciais de ensino e aprendizagem, junto a um conjunto de práticas em sala de aula que se derivam deles”. De acordo com Vilaça (2008), “A palavra método vem do grego méthodos, uma palavra composta por meta, que denota sucessão, ordenação, e hódos, que significa via, caminho".
} 
Partindo do pressuposto da primazia do livro no ensino de LE, nosso objetivo é analisar um LD de ensino de italiano para estrangeiros, tomando como base a sua configuração teórico-metodológica, a autoapresentação que o manual traz, seu índice e as atividades que se efetivam nas UD, verificando se há como estabelecer um diálogo entre as partes que constituem o livro.

Para efeitos didáticos, este artigo está dividido em cinco partes. A primeira, a presente, faz uma breve introdução acerca deste texto, indicando seu objetivo. Na segunda parte, abordaremos os pressupostos teóricos que terão influência direta neste trabalho. $\mathrm{Na}$ terceira, indicaremos a metodologia utilizada e definiremos o corpus desta pesquisa, justificando ainda o recorte utilizado. Seguemse a ela as análises, com a leitura e interpretação dos dados por parte dos autores. Por fim, na quinta parte, apresentaremos algumas considerações finais acerca da proposta desenvolvida.

\section{PRESSUPOSTOS TEÓRICOS}

De maneira geral, os livros didáticos fazem sua autoapresentação afirmando que são materiais comunicativos ou, utilizando explicitamente o termo, dizem que seguem a Abordagem Comunicativa. Tal informação aparece nas páginas dos livros nos sites das editoras, nos materiais em si e em demais materiais de divulgação, como encartes e folders. Portanto, apresentamos a seguir os pressupostos teóricos que serão a base deste artigo e que servirão como apoio para a metodologia empregada.

\subsection{ABORDAGEM COMUNICATIVA (AC)}

Nosso entendimento acerca do que seja a AC se dá a partir da proposição de Richards (2006). Segundo esse autor,

Pode-se entender o Ensino Comunicativo de Línguas Estrangeiras como um conjunto de princípios aplicados às metas de ensino de línguas estrangeiras, como a forma pela qual os alunos aprendem um idioma, os tipos de atividades em sala de aula que facilitam o aprendizado e os papéis desempenhados pelos professores e alunos em uma sala de aula, estabelecendo como meta o ensino da competência comunicativa [...], utilizando a linguagem para uma comunicação significativa. (RICHARDS, 2006, p. 2-3)

Da maneira como o autor coloca, a definição descrita pode identificar qualquer tipo de abordagem, não especificamente aquela comunicativa. Partiremos dessa primeira definição para aprofundar a questão. Entretanto, a definição traz em si uma série de elementos do ensino que são foco de atenção da AC. Alunos, professores, atividades em sala de aula, o ensino da competência comunicativa e as metas do ensino: diferentes elementos do espaço escolar que serão importantes para uma reflexão aprofundada sobre o ensino de LE. A estes elementos, acrescentamos ainda o LD, a abordagem e a interação entre os participantes, para exemplificar apenas alguns.

Dessa forma, a AC tem como objetivos, segundo Kumaravadivelu (2006, p. 91, tradução nossa),

Oferecer oportunidades para os alunos praticarem noções/funções de comunicação pré-selecionadas, por meio de atividades com foco no significado, assumindo que a preocupação com a forma e a função acabará por levar ao domínio da linguagem e que os alunos podem fazer uso de ambos os repertórios formal e funcional para cumprir suas necessidades comunicativas fora de classe. Nessa visão, o desenvolvimento da linguagem é mais intencional. 2

Em Kumaravadivelu (2006), portanto, encontramos a definição de AC com a qual trabalharemos.

Outra característica dessa abordagem é a desconstrução da figura do professor como o detentor do conhecimento, aquele que passa a seus alunos a informação. Aqui, entende-se que o ensino (e a oferta de acesso à língua)

2 "To provide opportunities for learners to practice preselected, communicative notions/functions through meaning-focused activities, assuming that a preoccupation with form and function will ultimately lead to target language mastery and that the learners can make use of both formal and functional repertoire to fulfill their communicative needs outside the class. In this view, language development is more intentional.". 
É um processo não-linear e que, portanto, não requer inputs linguísticos pré-selecionados e pré-sequenciados, mas requer as condições de criação em que os aprendizes sejam engajados na significação de atividades em classe. Língua é melhor aprendida quando o foco não está na língua, isto é, quando a atenção do aprendiz está no entendimento, dizendo e fazendo algo com a língua. (KUMARAVADIVELU, 2010, p. 92, tradução nossa)3

Dessa forma, a AC se caracteriza pela multiplicação da "linearidade" do ensino, no sentido de não mais conceber o ensino apenas na linearidade "professor - aluno", mas de multiplicá-la: do professor ao aluno, de aluno a aluno, do livro ao aluno etc., englobando todos os atores envolvidos no ensino-aprendizagem. Neste cenário, tanto o professor quanto os alunos, os materiais didáticos, os recursos tecnológicos e os mais variados fatores podem ser canais de aprendizado da língua em questão. Tal visão torna ainda mais importante a interação entre os aprendizes.

Vale observar que a AC não possui uma única definição de seus pressupostos, além de ter se desenvolvido de diferentes formas: (i) Abordagem Natural; (ii) Aprendizagem Colaborativa de Línguas; (iii) Ensino Baseado em Conteúdos; e (iv) Ensino Baseado em Tarefas (RICHARDS; RODGERS, 2003). Tais diferenciações se dão uma vez que, a bem da verdade, "A abordagem comunicativa não é, pois, uma bateria de técnicas ou um modelo de planejamento, mas sim a adoção de princípios mais amplos como o foco no processo, nas maneiras específicas de como se aprende e de como se ensina outra língua [...] que não pode ser reducionisticamente interpretado" (ALMEIDA FILHO, 2007, p. 82).

Para além destas discussões, a AC pretende, sobretudo, o desenvolvimento da competência comunicativa.

\subsection{COMPETÊNCIA COMUNICATIVA (CC)}

A noção de CC (HYMES, 1972; MAINGUENEAU, 2004) implica num conhecimento linguístico muito mais amplo do que apenas aqueles da competência gramatical. Definida por Maingueneau (2004, p. 41) como “[...] nossa aptidão para produzir e interpretar os enunciados de maneira adequada às múltiplas situações de nossa existência”, ela leva em consideração não apenas os conhecimentos dos códigos, da sintaxe, das estruturas da língua e de sua morfologia: conceitos como o de adequação, aceitação, coerência e contextualização são igualmente relevantes, bem como as escolhas particulares acerca do que dizer, quando dizer, para quem dizer e de que forma dizer. Usar a língua como uma mediadora das diferentes práticas e ações sociais requer que sejam colocados em ação diferentes conhecimentos que não apenas aqueles estritamente "gramaticais", "[...] já que conhecer as características formais de uma língua não é condição suficiente para comunicar-se”" (BORNETTO, 1998, p. 140, tradução nossa). Ela tem muito mais a ver com o uso da língua do que com o conhecimento linguístico ${ }^{5}$.

Almeida Filho (2007, p. 81) afirma que a CC:

Convida-nos a reconsiderar a língua não estritamente como objetivo exterior ao aluno, mas sim como um processo construtivo e emergente de significações e identidade. Aprender uma língua não é mais somente aprender outro sistema, nem passar informações a um interlocutor, mas sim construir no discurso (a partir de contextos sociais concretos e experiências prévias) ações sociais (e culturais) apropriadas.

Busca-se na CC um ensino que ofereça ao aluno a possibilidade de se comunicar em uma série de situações diferentes, sabendo como variar o uso da língua para se adequar à cena enunciativa em que se encontra. Almeida Filho (2010, p. 36) traça ainda uma aproximação, afirmando que:

\footnotetext{
3 "Is a nonlinear process, and therefore, does not require preselected, presequenced systematic language input bur requires the creation of conditions in which learners engage in meaningful activities in class. [...] Language is best learned when the focus is not on the language, that is, when the learner's attention is focusing on understanding, saying, and doing something with the language."

4 “[...] conoscere le caratteristiche formali non è condizione sufficiente per comunicare".

${ }^{5}$ Richards (2006) aponta casos em que, ainda que conhecedores estritos dos componentes linguísticos, os alunos não eram capazes de se comunicar.
} 
Os métodos comunicativos têm em comum uma primeira característica - o foco no sentido, no significado e na interação propositada entre sujeitos na língua estrangeira. O ensino comunicativo é aquele que organiza as experiências de aprender em termos de atividades relevantes/tarefas de real interesse e/ou necessidade do aluno para que ele se capacite a usar a língua-alvo para realizar ações de verdade na interação com outros falantesusuários dessa língua.

Em suma, na AC, busca-se uma recriação das condições de comunicação originais (ou o mais próximo possível do "original”), que pudessem colocar o aluno em uma situação real (ainda que recriada) de comunicação. Nesta situação "real", o aluno teria as condições necessárias para usar a língua como mediadora das suas práticas sociais, expressando-se de maneira contextualizada e adaptada (com questões, por exemplo, de modalidade, formalidade e entonação, dentre outras). Dessa forma, atividades comuns nesta proposta são as de pedir, perguntar, explicar, agradecer, avaliar e opinar, inseridas em situações comunicativas específicas, em locais "reais" (restaurante, padaria, hotel, aeroporto). Situações cotidianas, da vida profissional, familiar e acadêmica são reproduzidas e trabalhadas, tendo sempre como foco a comunicação efetiva.

Há diversas críticas que podem ser feitas à AC, às quais não nos deteremos em profundidade. Em seu artigo, Almeida Filho (1986, p. 90) já alertava para o problema que a AC trazia em si, bem como criticava a visão que procurava "modismos metodológicos e panaceias milagrosas", indicando, ainda, que, de fato, a AC inovava "em partes e não radicalmente em todos os seus aspectos". Associando pesquisa linguística e observação didática, o autor já alertava para os problemas que a AC trazia.

Atualmente, de forma geral, a noção de AC é criticada, principalmente no âmbito universitário. Uma de suas mais famosas críticas é feita por Kumaravadivelu (2006), que indica que o ensino de idiomas está na era do "pós-método", uma etapa posterior ao pensamento que "limitava" o ensino a um método didático específico. Como nossa intenção não é traçar uma crítica à AC, mas expor seus argumentos basilares para ampararem as análises que traremos, não aprofundaremos a questão, deixando a sugestão de leitura das muitas obras escritas por Almeida Filho (1986) e Kumaravadivelu (2006), dentre outros autores.

\section{METODOLOGIA E ESCOLHA DO CORPUS}

Nesta seção, definiremos a metodologia utilizada para as análises e evidenciaremos as escolhas de corpus e o recorte realizado para este texto.

\subsection{DESCRIÇÃO DO LIVRO: O CORPUS UTILIZADO}

O corpus utilizado nesta pesquisa é o livro de italiano para estrangeiros Chiaro! A1, editado pela Alma Edizioni, situada em Florença (Firenze). O livro foi lançado em 2010 e possui como autores Giulia de Savorgnani e Beatrice Bergero, com a participação de outros sete consultores ${ }^{7}$. O livro é direcionado para o nível A1 do Quadro Comum Europeu de Referência (EUROPA, 2001). A editora em questão é uma das maiores do mercado italiano, tendo seus livros vendidos em todo o mundo. Além disso, a coleção Chiaro! em especial é uma das mais vendidas no Brasil, sendo utilizada nos cursos de Letras Português-Italiano em diversas universidades, como a UERJ, além de também ser encontrada em muitos cursos regulares de língua italiana. É, pois, um material de ampla circulação no país, em que pese a consideração da baixa procura pela língua italiana como LE.

Como critérios de análise para a realização dessa investigação, tomaremos como base os dados apresentados pelos próprios autores do material didático na autoapresentação do livro. Segundo sua autoapresentação (Figura 1), Chiaro! Al é um curso de italiano eficaz e acessível, com uma proposta objetiva e de imediata compreensão, direcionado a quem nunca teve contato com a língua italiana. Baseado na Abordagem Comunicativa (RICHARDS, 2006; ALMEIDA FILHO, 2007; BORNETO, 1998), seu objetivo é o de colocar o estudante nas principais situações comunicativas cotidianas e exercitar de modo gradual as quatro habilidades,

\footnotetext{
${ }^{6}$ Embora entendamos que a sala de aula, em última instância, nunca será uma situação "real" de interação, consideraremos a premissa verdadeira.

${ }^{7}$ Os nomes serão suprimidos por entendermos que eles não são relevantes para este trabalho.
} 
desenvolvendo a CC de seus usuários (HYMES, 1972; MAINGUENEAU, 2004). Tem ainda uma atenção especial para comunicação e a interação em sala de aula, utiliza textos autênticos e áudios reais, colocando o aluno em situações "encontráveis na vida real". Completa dizendo que as atividades objetivam a construção de um aluno que é autônomo, pesquisador e que "sabe fazer" - no sentido de ele não apenas aprender a língua, mas de entendê-la e utilizá-la de maneira contextualizada.

\section{Introduzione}

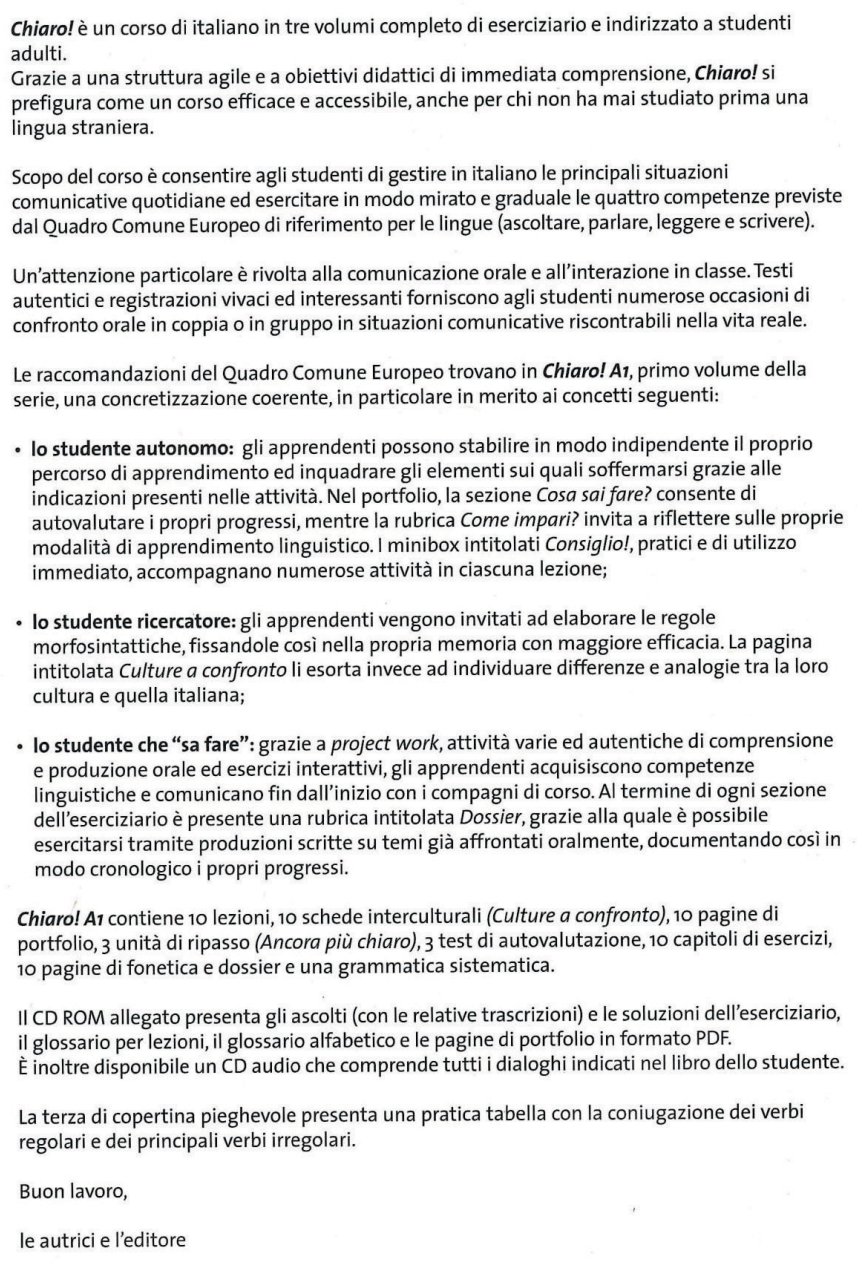

Figura 1: Introdução do livro - Chiaro A1!

Fonte: Savorgnani e Bergero (2010)

Completam o livro um caderno de exercícios (integrado ao volume) e um CD-ROM, com áudios, respostas dos exercícios e um glossário das palavras utilizadas nas UD. Possui dez unidades, dez capítulos de exercícios, três unidades de revisão e três testes de autoavaliação, com um apêndice para a conjugação de verbos e as principais regras gramaticais.

\subsection{JUSTIFICATIVA DO RECORTE UTILIZADO PARA A ESCOLHA DA UD}

Para as análises deste artigo, optamos por investigar detalhadamente a UD 10, a última do livro. Acreditamos que, ao chegar ao final do percurso didático indicado pelo livro, o aluno é já capaz de ter um desenvolvimento linguístico mais aprofundado, de acordo com o nível abordado. Neste estágio, por consequência, teria possibilidade de realizar atividades com maior grau de complexidade. Portanto, a escolha deste recorte para este trabalho não foi aleatória, mas segue um critério objetivo. 


\subsection{INDICAÇÕES DO ÍNDICE DA UD 10}

O sumário da UD analisada é dividido em seis partes. Apresentamos cada uma delas, com a indicação daquilo que deverá ser trabalhado (Figura 2).

(i) Situação comunicativa: descrição do tema que define a UD. O argumento utilizado é "viagem”, exposto a partir de um fim de semana em outra cidade;

(ii) Objetivos: aquilo que se espera que o aluno possa fazer ao fim das atividades, como dizer em que lugar está, entender breves ofertas turísticas e reservar um quarto de hotel;

(iii) Competências pragmáticas: a competência linguística que o aluno desenvolveria em situações reais, como na reserva de um quarto, na descrição da viagem ou na escrita de um cartão-postal;

(iv) Competência linguística: o léxico, a gramática e a fonética que serão trabalhados;

(v) Cultura em confronto: exposição de um aspecto cultural da Itália;

(vi) Como aprender: dicas e sugestões de estratégias de autoaprendizagem.

10 Finalmente è venerdi!

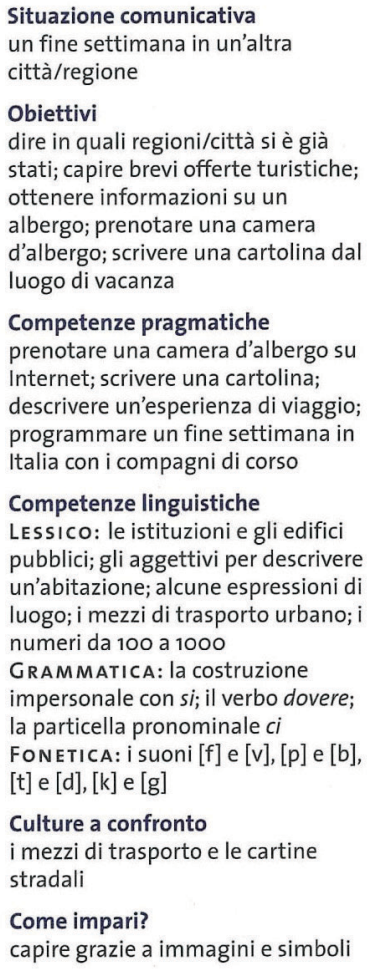

Figura 2: Sumário da UD

Fonte: Savorgnani e Bergero (2010)

\subsection{DESCRIÇÃO DA UD 10}

A UD em questão possui como tema geral que norteia a unidade (Situação Comunicativa) o argumento "viagem". Na primeira página da UD há uma apresentação daquilo que os alunos vão aprender a fazer na lição: (i) dizer qual região e cidade visitaram; (ii) entender breves ofertas turísticas; (iii) reservar um quarto de hotel; (iv) falar do tempo meteorológico; e (v) escrever uma carta do lugar de viagem em que está. Há a imagem de alguns locais históricos e turísticos (igrejas e praças apenas), com a frase "finalmente é sexta-feira" em destaque. É também apresentada a primeira atividade, "para iniciar”, com perguntas relacionadas aos locais italianos que já foram visitados pelo aluno, onde eles ficaram e o que foi visto. 
Em seguida, são apresentadas outras quatorze atividades. Vejamos com mais detalhes cada uma delas, utilizando como critério de identificação a indicação que é feita pelo livro:

\begin{tabular}{|c|c|c|}
\hline Atividade & Descrição da proposta & $\begin{array}{c}\text { Habilidade trabalhada (indicação } \\
\text { do livro) }\end{array}$ \\
\hline 2 & Texto autêntico ${ }^{8}$ com informações de hotéis e quartos para reserva & Ler \\
\hline 3 & Apresentação das estações do ano & Falar \\
\hline 4 & Números de 100 a 1000 & Léxico \\
\hline 5 & Indicação de frases prontas para situações em hotéis & Falar / Escutar \\
\hline 6 & Regras de uso da formação impessoal com "si" & Gramática \\
\hline 7 & Reforço da atividade gramatical & Gramática \\
\hline 8 & Representação como alguém que reserva um quarto em hotel & Falar / Escrever \\
\hline 9 & Exemplos de frases para indicar o tempo; escrita de cartão-postal & Léxico/Ler \\
\hline 10 & Trabalho em grupo para escrita de carta & Escrever / Gramática \\
\hline 11 & Regra de uso da "particella ci" & Gramática \\
\hline 12 & Leitura de relato de viagem & Ler \\
\hline 13 & Regra de uso do advérbio "nunca" & Gramática \\
\hline 14 & Escrita de e-mail contando sobre uma viagem & Escrever \\
\hline 15 & Organização em grupo de um roteiro de viagem e reserva de quarto & Falar / Escrever / Ler \\
\hline
\end{tabular}

Completam a UD outros dois elementos: "Cultura em confronto" e "Portfólio". No primeiro, são apresentados alguns tickets de diferentes meios de transporte, como trem, metrô e avião, com um breve texto apresentando as "preferências de viagem dos italianos”; por fim, há uma pergunta sobre qual o meio de transporte preferido no país do aluno - a ideia, lembramos, é estabelecer um "confronto" entre as culturas. No segundo elemento, há uma autoanálise que o aluno deve preencher de acordo com o grau em que ele acredita estar em relação aos elementos trabalhados na UD. Há ainda a apresentação de algumas placas de informação, com o estímulo para que o aluno procure outras na internet e descubra seu significado.

\subsection{METODOLOGIA UTILIZADA PARA AS ANÁLISES}

Os critérios de análise que utilizaremos se dão a partir do confronto entre três elementos: a autoapresentação feita pelo livro, a descrição da UD e as atividades que compõem a UD, em diálogo com os pressupostos teóricos. A partir da interação entre estes três elementos, realizaremos as nossas análises, observando de que forma eles se relacionam (se houver relação) e se há coerência entre

${ }^{8}$ Tilio (2012b, p. 1021) afirma que, “[...] nesse caso, os textos são claramente não autênticos, escritos especialmente para o livro didático com um objetivo pedagógico, e não retirados de contextos sociais reais de uso”. 
as três partes. Optamos por não utilizar nenhum critério de análise estabelecido por outros autores ${ }^{9}$, por entender que o livro em questão não foi elaborado para se adequar a estes critérios. Analisá-los por estes prismas seria atitude incoerente de nossa parte; os resultados, por consequência, poderiam ser uma crítica negativa, tomando concepções diferentes das apresentadas pelo livro.

\section{ANÁLISES}

Retornamos às atividades desenvolvidas na UD. Observamos com mais atenção cada uma delas, buscando identificar quais elementos são efetivamente trabalhados e a forma como eles são abordados. Dessa maneira, identificamos a seguinte configuração:

\begin{tabular}{|c|c|c|}
\hline Atividade & Habilidade trabalhada (indicação do livro) & O que efetivamente se aborda \\
\hline 2 & Ler & Leitura (texto adaptado) \\
\hline 3 & Falar & Vocabulário (com escrita) \\
\hline 4 & Léxico & Léxico \\
\hline 5 & Falar/Escutar & Expressões e frases prontas \\
\hline 6 & Gramática & Gramática \\
\hline 7 & Gramática & Gramática \\
\hline 8 & Falar/Escrever & Situação comunicativa (com gramática) \\
\hline 9 & Léxico / Ler & Léxico (com leitura de cartão-postal) \\
\hline 10 & Escrever / Gramática & Escrita (com gramática) \\
\hline 11 & Gramática & Gramática \\
\hline 12 & Ler & Leitura \\
\hline 13 & Gramática & Gramática \\
\hline 14 & Escrever & Escrita \\
\hline 15 & Falar / Escrever / Ler & Situação comunicativa / Leitura \\
\hline
\end{tabular}

Após esta primeira leitura, já é possível perceber que as atividades propostas não atingem os objetivos estabelecidos. Enquanto a atividade é definida de um modo, aquilo que se desenvolve é diferente, como no caso das atividades (3), (5) e (8), abordadas a seguir.

No item (3) (Figura 3), é proposta pelo livro uma atividade com foco na habilidade de falar. A atividade apresenta quatro desenhos relacionados às quatro estações do ano e pede para o aluno correlacionar cada um dos desenhos com o nome das estações. O que se identifica, portanto, não é uma atividade que envolve oralidade, mas a apresentação de conteúdo lexical; para realizá-la, o aluno não precisa falar nenhuma palavra. Pelo exposto a respeito da CC (HYMES, 1972; MAINGUENEAU, 2004) na segunda parte deste artigo, percebemos que, ainda que se apresente como uma atividade comunicativa, o que se coloca é uma atividade de caráter tradicional (RICHARD; RODGERS, 2003). Em seguida, pede-se que o aluno faça uma lista das palavras que conhece relacionadas

${ }^{9}$ Sobre critérios análise de LD de LE, recomendamos a leitura de Biral (2000), Dias (2009), Vilaça (2010) e Tilio (2013). 
a cada uma das estações. Mais uma vez, basta o aluno escrever algumas palavras (abordagem de vocabulário), sem a necessidade de comunicação oral.

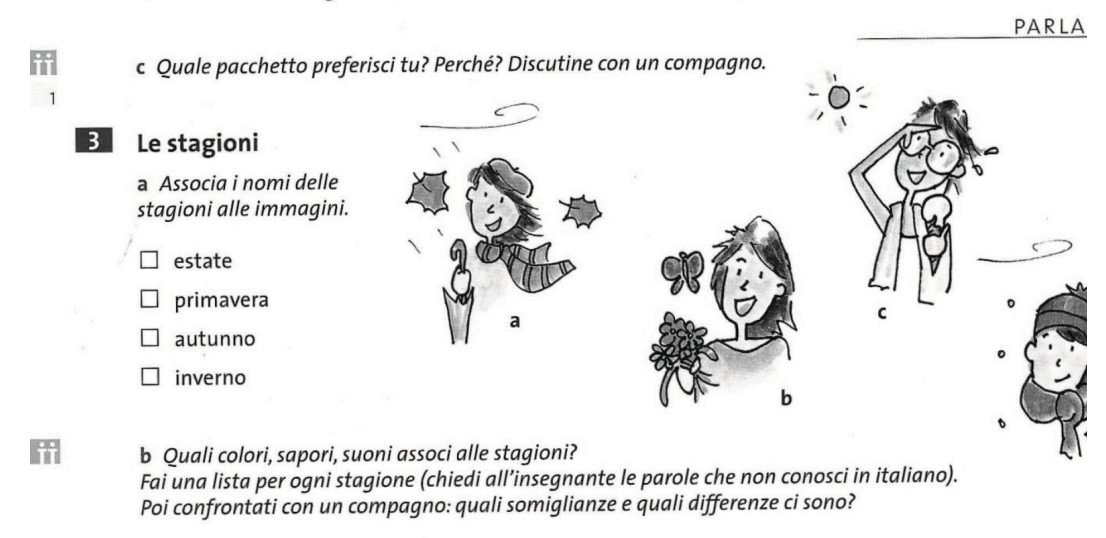

Figura 3: Atividade 3

Fonte: Savorgnani e Bergero (2010)

Na proposta (5) (Figura 4), é sugerida ao aluno mais uma atividade com foco na fala. O texto indica "algumas perguntas úteis" 10 para se reservar um quarto em um hotel. Sem fazer nenhuma contextualização, são expostas onze frases-modelo para que o aluno memorize. Uma vez mais, a atividade se afasta dos pressupostos da AC e da CC. Para realizar a atividade, basta ao aluno ler as frases, sem a necessidade, por exemplo, de inseri-las em um diálogo ou em uma situação comunicativa maior. Assim, a atividade se configura como sendo de leitura e memorização, não de fala. Outro ponto sugerido pela atividade é o trabalho com a escuta. Simulando a reserva de um quarto, há um diálogo entre um turista e uma recepcionista, com esta indicando os serviços incluídos no pacote da reserva. Pede-se ao aluno que, diante de uma lista, marque um "x" nos serviços que são oferecidos. O registro dura menos de um minuto e é o único apresentado em toda a unidade.

5 Vorrei prenotare una camera

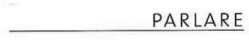

a Ecco alcune domande utili per prenotare una camera d'albergo.

importanti completare la lista. Poi segna con una " $X$ "le domande

$\square$ L’albergo è in centro?

$\square$ C'è un parcheggio?

$\square$ Si possono portare animali?

$\square$ Il bagno ha la vasca o la doccia?

$\square$ Quanto viene la camera?

$\square$ Quanto viene una camera singola?

$\square$ La prima colazione è compresa?

$\square$ Si può avere la mezza pensione / la pensione completa?

$\square$ C'è collegamento Internet in camera?

$\square$ L'albergo ha un centro benessere

(piscina, solarium, palestra...)?

$\square$ È possibile pagare con la carta di credito?

$\square$

b Ascolta la telefonata.

ASCOLTARE

b Ascolta la telefonata.

Quale pacchetto del punto 2 a va bene per la persona che vuole prenotare?

c Riascolta la registrazione. Quali domande del punto 5 a senti?

d Riascolta ancora.

Quali servizi sono compresi nella quota del pacchetto?

$\begin{array}{lll}\square \text { skibus } & \square \text { ingresso al museo } & \square \text { pranzo o cena in un ristorante tipico } \\ \square \text { z pernottamenti in albergo } & \square \text { escursioni } & \square \text { degustazione di prodotti trentini } \\ \square \text { skipass giornaliero } & \square \text { Trento Card 48 ore } & \square \text { visite guidate a Trento }\end{array}$

Figura 4 :Atividade 5

Fonte: Savorgnani e Bergero (2010)

\footnotetext{
10 “Alcune domande utili” (tradução nossa)
} 
A atividade (8) (Figura 5) objetiva oferecer ao aluno a possibilidade de falar e escrever. Ela se divide em duas partes: uma espécie de teatro, em que os alunos simulam os papéis de "turista" e "recepcionista", e outra em que devem completar as informações de uma ficha de cadastro. Esse tipo de atividade é bem comum na AC, com situações comunicativas simuladas, como uma forma de possibilitar que o aluno pratique/desenvolva a oralidade. Para tal, a UD apresenta a conjugação de verbos irregulares, sem nenhuma ligação direta com a atividade, descontextualizados. Em nenhuma parte da atividade há a indicação sobre o que fazer com os verbos; a própria atividade pode ser realizada sem o auxílio deles. O que percebemos é que, a princípio, a atividade possui coerência com os pressupostos apresentados pelo livro e aqui discutidos; ainda assim, ela é utilizada como "pano de fundo" para uma exposição gramatical descontextualizada.

iil 8 Una prenotazione PARLARE

a Lavora con un compagno. Dividetevi i ruoli (A fa il turista, B il receptionist) e create un dialogo in base alle informazioni seguenti.

$\begin{array}{ll}\text { A telefona all'Hotel } & \text { B risponde alle domande } \\ \text { Montana per prenotare } & \text { di A con l'aiuto delle } \\ \text { una camera e chiede } & \text { informazioni a pagina 123. } \\ \text { informazioni sui servizi } & \\ \text { e sui prezzi. } & \end{array}$

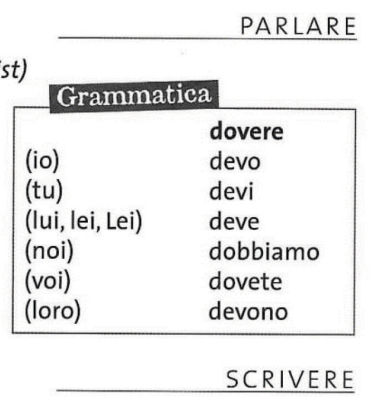

b Ora compilate il modulo per la prenotazione. A prenota una camera (o più camere) nell'albergo a pagina 123, B prenota uno dei pacchetti del punto $2 a$.

112 centododici

Figura 5: Atividade 8

Fonte: Savorgnani e Bergero (2010)

Após este primeiro momento de análise, é possível reagrupar as quinze atividades da UD da seguinte forma (excetuando-se a primeira, introdutória):

\section{Quantidade de ocorrências}

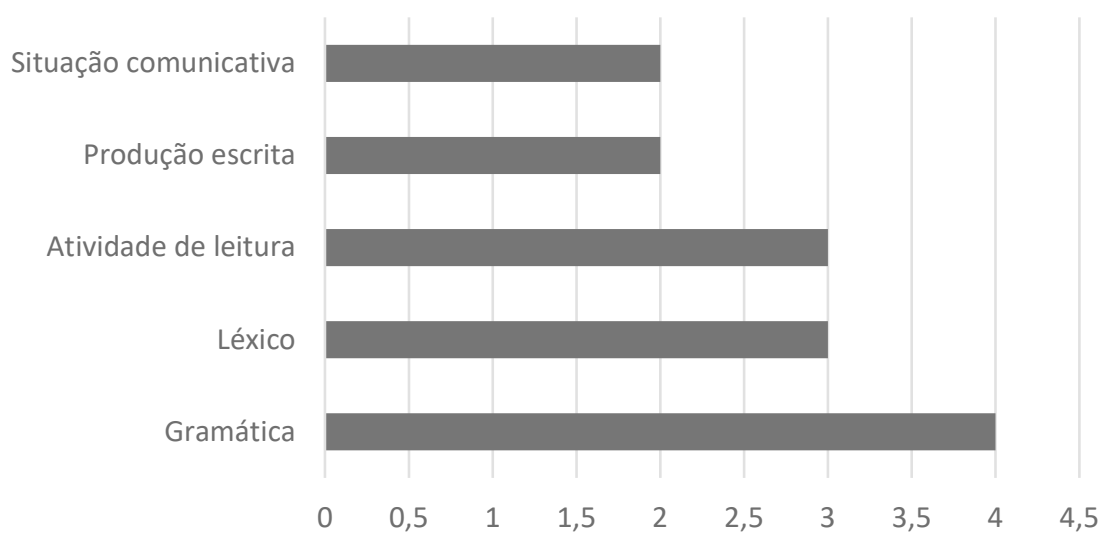

Gráfico 1: Ocorrência de atividades na unidade

Fonte: produzido pelo autor

Como exposto no gráfico anterior, há uma predominância de atividades gramaticais e com foco no vocabulário/léxico. Dessa forma, a CC definida pelo livro como seu objetivo não se efetiva, já que as atividades desenvolvidas na UD são majoritariamente gramaticais/lexicais em relação àquelas comunicativas. 
Em um segundo momento de análise, confrontamos as atividades, da maneira que se efetivam, com o índice da UD (Figura 2). É possível perceber que, na realidade, elas têm êxito apenas parcialmente, como exposto abaixo:

(i) Situação comunicativa: parcialmente efetivada, sendo apenas duas atividades com foco único para ela;

(ii) Objetivos: parcialmente atingidos, uma vez que o foco da maioria das atividades é a gramática e o léxico/vocabulário, não a comunicação;

(iii) Competências pragmáticas: parcialmente atingidas. As atividades têm pouca ou nenhuma contextualização, sendo sempre guiadas (modelos) e pouco aprofundadas;

(iv) Competência linguística: efetivada, mas com exposição tradicional, sem contextualização ou apresentação de outras formas de uso que não a norma culta (standard);

(v) Cultura em confronto: efetivada, mas com uma visão de cultura estereotipada e generalizante;

(vi) Como aprender: não efetivada. Não há nenhuma atividade ou menção em toda a UD.

As análises evidenciam, portanto, não haver correlação entre o que o índice apresenta para a UD e o que se realiza internamente na unidade.

Para a terceira etapa das análises, confrontamos as atividades com a descrição do livro feita na autoapresentação (Figura 1). Deste diálogo, é possível identificar que uma série de posicionamentos defendidos pelo livro não são efetivados na UD.

Apresentando-se como um curso eficaz e objetivo, o livro pode ter sua eficácia questionada quando analisamos o seu grau de efetivação exposto pelo índice. Outro elemento que justifica os questionamentos é a própria configuração das atividades, que não correspondem às indicações feitas. Além disso, as atividades são pouco objetivas e sem contextualizações anteriores.

Outra proposta do livro é a de colocar os aprendizes em contato com as principais situações comunicativas da vida cotidiana desenvolvimento da CC. Na UD analisada, identificamos a ocorrência de apenas duas atividades, num universo de quinze, direcionadas a alguma situação comunicativa. Uma delas, a atividade (8) (Figura 5), ainda tem como pano de fundo uma exposição gramatical descontextualizada. Assim, seja num viés qualitativo, seja num viés quantitativo, a intenção de ser comunicativo não é alcançada, já que as atividades são poucas e superficiais, sem pertinência conceitual com a AC (RICHARDS, 2006; ALMEIDA FILHO, 2007; BORNETO, 1998).

Para o trabalho com as quatro habilidades, detectamos haver a predominância de atividades pouco aprofundadas, que não mobilizam outros saberes dos alunos e não se articulam, de maneira geral, umas às outras. Para a habilidade de escuta ${ }^{11}$, há apenas uma ocorrência em toda a UD. Julgamos ser insuficiente, ainda que o tempo da gravação (menos de um minuto) seja adequado ao nível (A1). Para a habilidade de leitura, pontuamos que ela é sempre entendida como uma identificação de elementos ou como decodificação de textos ${ }^{12}$. A atividade (2) (Figura 6) apresenta três textos curtos com a descrição de quartos para reserva. Em seguida, pede-se que o aluno indique qual dos três é mais aconselhado para determinadas pessoas (que amam a natureza, que viajam com a família, que gostam de diversão, dentre outras). O aluno precisa apenas localizar as informações no texto e apontar a qual pertencem. Não se problematiza os locais, nem se aprofunda a temática; basta localizar as palavras (que no exercício aparecem na ordem exata da ocorrência no texto) e indicar a qual exemplo pertencem.

O mesmo acontece com as atividades de escrita ${ }^{13}$. Nas atividades (9) (Figura 7) e (10) (Figura 8), são apresentados modelos de carta e cartão-postal e há o estímulo para que o aluno escreva uma carta, seguindo o modelo apresentado. Assim, o aluno deve, por exemplo, modificar o local de viagem, o período e o tempo meteorológico da viagem, mantendo toda a estrutura e as demais palavras. Não há um estímulo para que ele escreva outros gêneros textuais ou modifique o que lhe é apresentado.

\footnotetext{
${ }^{11}$ Para maiores esclarecimentos, sugerimos a leitura de Cardoso $(1997,2005)$.

${ }^{12}$ Para um aprofundamento sobre as teorias de leitura, sugerimos Kleiman (2004, 2008).

${ }^{13}$ A este respeito, são relevantes as contribuições de Schneuwly e Dolz (1999).
} 
Por fim, o trabalho com a habilidade de falar ${ }^{14}$ também é precário, já que apenas as atividades (3) (Figura 3), (8) (Figura 5) e (10) (Figura 8) a abordam e, como vimos anteriormente, não se desenvolve um efetivo trabalho com a produção oral.

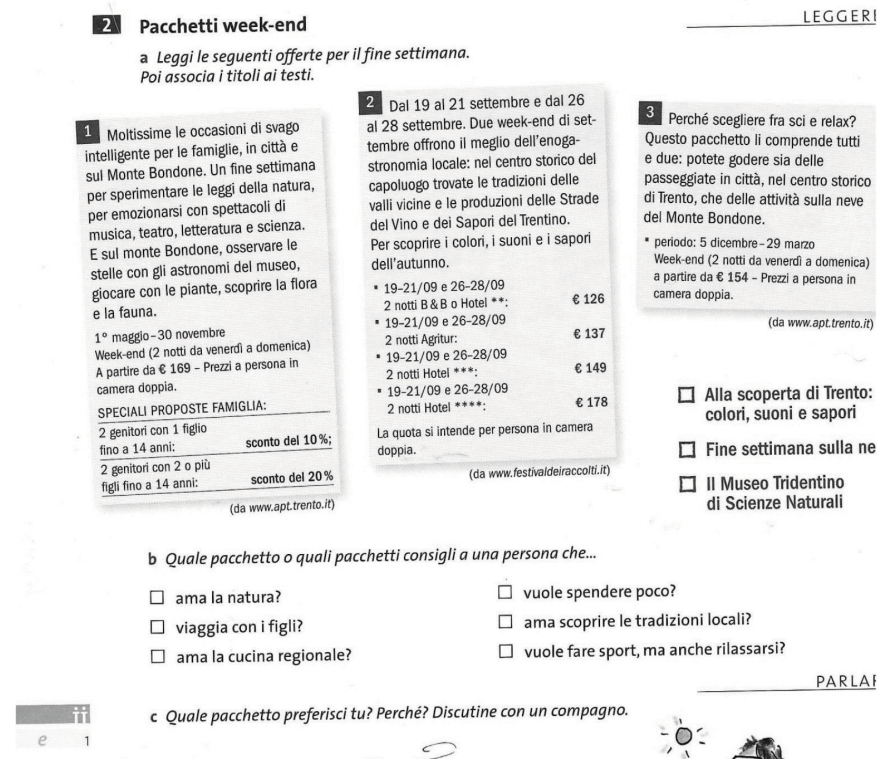

Figura 6: Atividade 2

Fonte: Savorgnani e Bergero (2010)

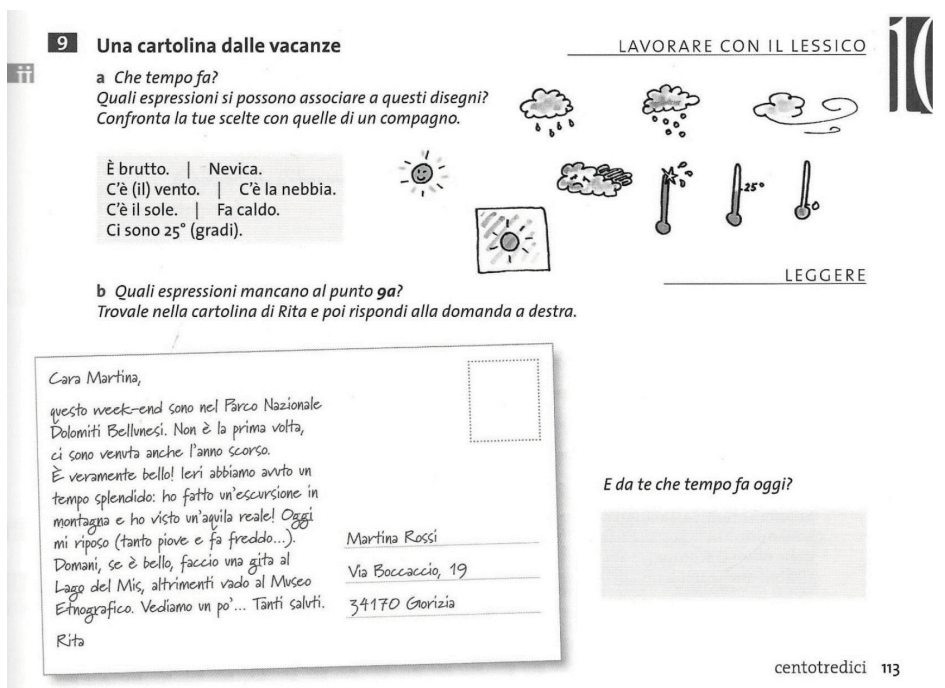

Figura 7: Atividade 9

Fonte: Savorgnani e Bergero (2010)

\section{iinii 10 Una cartolina di gruppo}

Lavorate in 6 e scrivete 6 cartoline dalle vacanze ispirandovi al punto gc. Ognuno prende un foglio, scrive l'inizio della cartolina (punto 1: Per iniziare), piega il foglio e lo dà al suo vicino di destra, che scrive il punto 2 (Dire dove si è), piega il foglio, ecc. Continuate cosi fino al punto 6 (Per finire). Dopo il punto 6 ogni cartolina torna all'autore del punto 1, che la firma. Alla fine ognuno legge la usua» cartolina a voce alta e il gruppo sceglie quella che gli piace di più.

Figura 8 : Atividade 10

Fonte: Savorgnani e Bergero (2010)

\footnotetext{
${ }^{14}$ Indicamos a leitura de Angelino (2000) para algumas sugestões de programação.
} 
Por uma questão de adequação ao espaço deste artigo, não serão abordadas outras questões pertinentes, como a autenticidade dos materiais, a promoção de autonomia, o conceito de cultura que se apresenta, e a ideia de que o aluno é pesquisador e "sabe fazer", para citar algumas. Acreditamos que os elementos aqui apresentados já são suficientes para que outras problematizações futuras possam ser feitas.

\section{CONSIDERAÇÕES FINAIS}

A escolha de um LD por parte dos professores influencia diretamente no processo de ensino-aprendizagem. Muitas vezes, será apenas a este material que os alunos terão acesso (CRISTOVÃO; DIAS, 2009), sendo indispensável, portanto, que a sua escolha não seja feita sem que se estabeleçam critérios. É necessário que se analise criticamente os materiais que serão utilizados. Sendo assim, as análises realizadas apontam uma série de incoerências na organização do LD Chiaro! A1. Tais incoerências podem prejudicar consideravelmente o processo de ensino-aprendizagem, reduzindo-o de forma simplista. Com relação à abordagem utilizada, nomeadamente comunicativa, é possível identificar mais uma vez um afastamento teórico, efetivado pela diferença entre os pressupostos da AC e a realização das atividades da unidade.

As análises nos permitem apontar, portanto, que a organização do livro se afasta consideravelmente das propostas definidas pela AC (RICHARDS, 2006; ALMEIDA FILHO, 2007; BORNETO, 1998), além de ter pouca preocupação efetiva com o desenvolvimento da CC (HYMES, 1972; MAINGUENEAU, 2004). O trabalho desenvolvido com as habilidades de fala e escuta é insuficiente, com predominância de aspectos gramaticais da língua; da mesma forma, poucos são os contextos reais de fala abordados, comprometendo o desenvolvimento da CC dos alunos.

Cumpre ainda afirmar que, embora saibamos que existem outras teorias que se relacionam com o ensino de línguas - como a dos gêneros textuais e dos multiletramentos, para citar apenas duas -, não as abordamos em nosso texto. Por limitação espacial e/ou foco da análise, desconsideramos tais questões, ainda que as vejamos como relevantes para o contexto.

Por fim, salientamos que a intenção deste trabalho não é apenas a de levantar críticas sobre o livro, desqualificando-o enquanto ferramenta pedagógica. Com as análises aqui empreendidas, esperamos que outras possam ser motivadas e que as discussões acerca da avaliação de materiais didáticos possam ser aprofundadas e ampliadas. Mais do que apenas criticar, o trabalho do professor deve ser o de oferecer possibilidades, buscando sempre aperfeiçoar o que possui. Este trabalho inicia, portanto, a primeira etapa deste caminho, na esperança de que outros o continuem.

\section{REFERÊNCIAS}

ALMEIDA FILHO, J. C. P. Lingüística aplicada: ensino de língua e comunicação. Campinas: Pontes e Arte Língua, 2007.

ALMEIDA FILHO, J. C. P. Dimensões comunicativas no ensino de línguas. 6. ed. Campinas: Pontes, 2010.

ALMEIDA FILHO, J. C. P. Fundamentação e crítica da abordagem comunicativa de ensino de línguas. Trabalhos em Linguística Aplicada, Campinas, v. 8, n. 1, p.85-91, 1986.

ANGELINO, M. Lo sviluppo delle abilità produttive. In: DOLCI, R.; CELENTIN, P. (ed.). La formazione di base del docente di italiano per stranieri. Roma: Bonacci editore, 2000. p. 148-168.

BIRAL, M. Indicazioni per l'analisi di manuali per l'insegnamento dell'italiano LS. In: DOLCI, R.; CELENTIN, P. (ed.). La formazione di base del docente di italiano per stranieri. Roma: Bonacci editore, 2000. P 257-266. 
BORNETO, Carlo Serra. C'era una volta il metodo. Tendenze attuali della didattica delle lingue straniere. Roma: Carocci editore, 1998.

CRISTOVÃO, Vera Lúcia Lopes; DIAS, R. (org.). O LD de línguas estrangeira: múltiplas perspectivas. Campinas: Mercado de Letras, 2009 .

DIAS, R. Critérios para a avaliação do LD (LD) de língua estrangeira (LE). In: CRISTOVÃO, V. L. L.; DIAS, R. (org.). O LD de línguas estrangeira: múltiplas perspectivas. Campinas: Mercado de Letras, 2009. p. 199-234.

CARDOSO, Janaína da Silva. The influence of learning strategies on the listening comprehension process in instructional contexts. 1997. Dissertação (Mestrado em Letras) - Programa de Pós-Graduação em Estudos da Linguagem, Universidade Federal Fluminense, Rio de Janeiro, 1997.

CARDOSO, Janaína da Silva. As estratégias de aprendizagem: desenvolvendo um processo mais eficaz e autônomo de compreensão oral. 2005. Tese (Doutorado em Letras) - Programa de Pós-Graduação em Estudos da Linguagem, Universidade Federal Fluminense, Rio de Janeiro, 2005.

EUROPA. Quadro comum europeu de referência para as línguas: aprendizagem, ensino, avaliação. Edição portuguesa. Porto: Edições Asa, 2001

KLEIMAN, A. B. Abordagens da leitura. SCRIPTA, Belo Horizonte, v. 7, n. 14, p. 13-22, jan./jul. 2004.

KLEIMAN, A. B. Oficina de leitura: teoria e prática. 12. ed. São Paulo: Pontes, 2008.

KUMARAVADIVELU, B. Understanding language teaching: from method to postmethod. Mahwah: ESL \& Applied Linguistics Professional Series, 2006.

MAINGUENEAU, D. Análise de textos de comunicação. Trad. Cecília P. de Souza-e-Silva e Décio Rocha. 3. ed. São Paulo: Cortez, 2004.

PAIVA, Vera Lucia Menezes de Oliveira e. História do material didático de língua inglesa no Brasil. In: DIAS, R.; CRISTÓVÃO, V. L L. (org.). O LD de linguas estrangeira: múltiplas perspectivas. Campinas: Mercado de Letras, 2009. p. 17-56.

RICHARDS, J. C. O ensino comunicativo de línguas. São Paulo: SBS Editora, 2006.

RICHARDS, J. C.; RODGERS, T S. Enfoques y métodos en la enseñanza de idiomas. 2. ed. Cambridge: Cambridge University Press, 2003.

SAVORGNANI, G. de; BERGERO, B. Chiaro!!! A1 - Corso di Italiano. Firenze: Alma, 2010.

SCHNEUWLY, B.; DOLZ, J. Os gêneros escolares: das práticas de linguagem aos objetos de ensino. Revista Brasileira de Educação, n. 11, p. 5-16, maio/ago. 1999. Disponível em: http://educa.fcc.org.br/pdf/rbedu/n11/n11a02.pdf. Acesso em: 17 dez. 2014.

TILIO, R. The role of coursebooks in language teaching. In: GARCIA, T. M. F. B. G. et al. Desafios para a superação das desigualdades sociais: o papel dos manuais didáticos e das mídias educativas. Curitiba: IARTEM, NPPD, UFPR, 2013. p. 462-470.

TILIO, R. Atividades de leitura em livros didáticos de inglês: PCN, letramento crítico e o panorama atual. Revista Brasileira de Linguística Aplicada, Belo Horizonte, v. 12, n. 4, p. 997-1024, 2012. 
VILAÇA, M. L. C. Materiais didáticos de língua estrangeira: aspectos de análise, avaliação e adaptação. Revista Eletrônica do Instituto de Humanidades, v. 8, n. 32, p. 67-78, jan./mar. 2010.

VILAÇA, M. L. C. A elaboração de materiais didáticos de Línguas Estrangeiras: autoria, princípios e abordagens. Cadernos do CNLF, v. 11, n. 4, p. 51-60, 2012.

\section{(c) (1) $\circledast \circledast$}

Recebido em 10/04/2019. Aceito em 16/01/2020. 